\title{
Resource-saving technologies for advanced concrete in the Republic of Bashkortostan
}

\author{
Alexander Krot ${ }^{1, *}$, Viktoriya Ryazanova ${ }^{2}$, Azat Gabitov², Aleksandr Salov', and Lyubov \\ Rolnik $^{2}$ \\ ${ }^{1}$ Kharkiv National University of Civil Engineering and Architecture, Sumska st. 40, 61002, Ukraine \\ ${ }^{2}$ Ufa State Petroleum Technological University, Mendeleeva St. 195, Ufa, 450000, Russia
}

\begin{abstract}
Properties of both organo-mineral superplasticized unmodified and modified concretes are considered, impact of workability of concrete and water-binder ratio on strength properties of concrete are analyzed herein. Gonsistent aggregate grading with minimum void, accordingly with maximum packed density under optimum content of dispersed particles in concrete is to be applied to make mortars and concrete with stable properties and less variations in values. The proposed solution enables to simplify proportioning as different combination of aggregates is not required for each proportion. Comparative analysis of various fillers being by-products and materials for making mortars and asphalt-concrete has been made. The results for reinforced steel consumption reducing together with efficient combination of higher grade concrete were considered at amending the "reinforced-concrete structures" section. Computational algorithms made under economic and mathematical methods to improve construction solutions over the reinforced concrete frame are given. Efficient engineering solutions to use high strength concrete and rebar that were applied in some facilities are proposed.
\end{abstract}

\section{Introduction}

Concretes with high performance and strength properties and concrete mixes with modifying additives were widely applied in monolithic construction in the Republic of Bashkortostan. Optimization and efficient use of high performance concretes and highstrength concretes especially combined with rebars of new strength grade are currently very important. Tailored composition of the concrete mix, choice of the applicable technology for making, curing and quality maintenance of the concrete blocks and reinforced concrete structures are provided in all advanced concrete manufacturing steps in compliance with strength and operational characteristics $[1,2]$.

\section{Materials and methods}

\footnotetext{
* Corresponding author: my_motherland@ukr.net
} 
Currently applied concrete mixes with ultimate compressive strength of 40MPa (with V30 strength grade) belong to P1 workability group (cone slump up to $1-5 \mathrm{~cm}$ ) and may not be applied in monolithic construction. Concrete mixes of P4-P5 workability group made with organo-mineral modifiers and current superplasticizers for 50-80 strength range (V40-V65 concrete grade) may be basically applied in monolithic construction technology, including using of concrete in thin-walled and densely-reinforced structures. Concrete mixes with advanced chemical additives of P1-P3 workability group enable making V80 concrete and higher (100MPa grade strength and higher) [3, 4].

Proceeding from monolithic construction practice, it may be noted that concretes with compressive strength up to $40 \mathrm{MPa}$ ( $90 \%$ of total volume) are largely used. Concreting technology development, improvement of engineering and technological solutions in using concrete and reinforced concrete, optimization in applying high performance concrete and structures made thereof directly depend on testing the Portland cement and its various kinds. So far, the results of certain and our own research in efficient application of modified concrete mixes (Fig.1) are analyzed, classified and summarized.

Current requirements to concrete are different. In certain circumstances, low grade concrete but with higher requirements to special features is required, e.g. BST V15 P4 F75 W6 GOST 7473-2010. To comply with watertightness requirements concrete with higher compressive strength than V15 concrete made by usual technology as the latter will be of lower watertightness grade than W6.

Making and application of modified concrete involve problems not only to attain but to maintain the required strength and estimated performance standards of cement concrete to be accompanied by further researching of structure formation and destruction within cement systems.

To eliminate any possible negative effects of internal stress in high water-reducing systems amorphous microsilica may be efficiently added which reaction when interacting with calcium hydroxide escaping under hydration is accompanied by minimum volume changing. Amorphous microsilica concrete is widely applied in large-scale housing construction nowadays. One of the known efficient ways to improve properties of cementitious composites thereby achieving compositional homogeneity thereof is adding of various mineral addditives to get microfilling effect on nanometric level either $[5,6]$. Actually all properties of cementitious composites depend on water-binder ratio, with minor variations being made to water-binder ratio thereby result in significant changing of properties.

Research of impact of general water-binder ratio and filling material on different properties, including concrete strength is to be continued in further wide application of the universal water-binder ratio in concrete making practice.

Developed and proposed original structural and technological concept to apply either general water-binder ratio or equal volume of dispersed part for concrete in wide range of strengths enables:

- to make concrete and concrete mix of wide strength range with required stable and technological properties (workability keeping, watertightness, freeze-thaw durability, rate of strength development, etc.);

- to simplify proportioning of the composition by eliminating the need to specify ratio of the aggregates for each concrete grade and mortar grade by strength by using combination of aggregates with minimum void and optimum content of dispersed particles in concrete and mortars;

- to use high efficiency of plain high grade cement in combination with superplasticizers (increased strength related to particle dispergation effect, keeping of workability under application of retarders, prevention from strength retrogression by increasing aggregate fraction of less than $0.16 \mathrm{~mm}$ and by adding fillers) in regular concrete and mortars. 


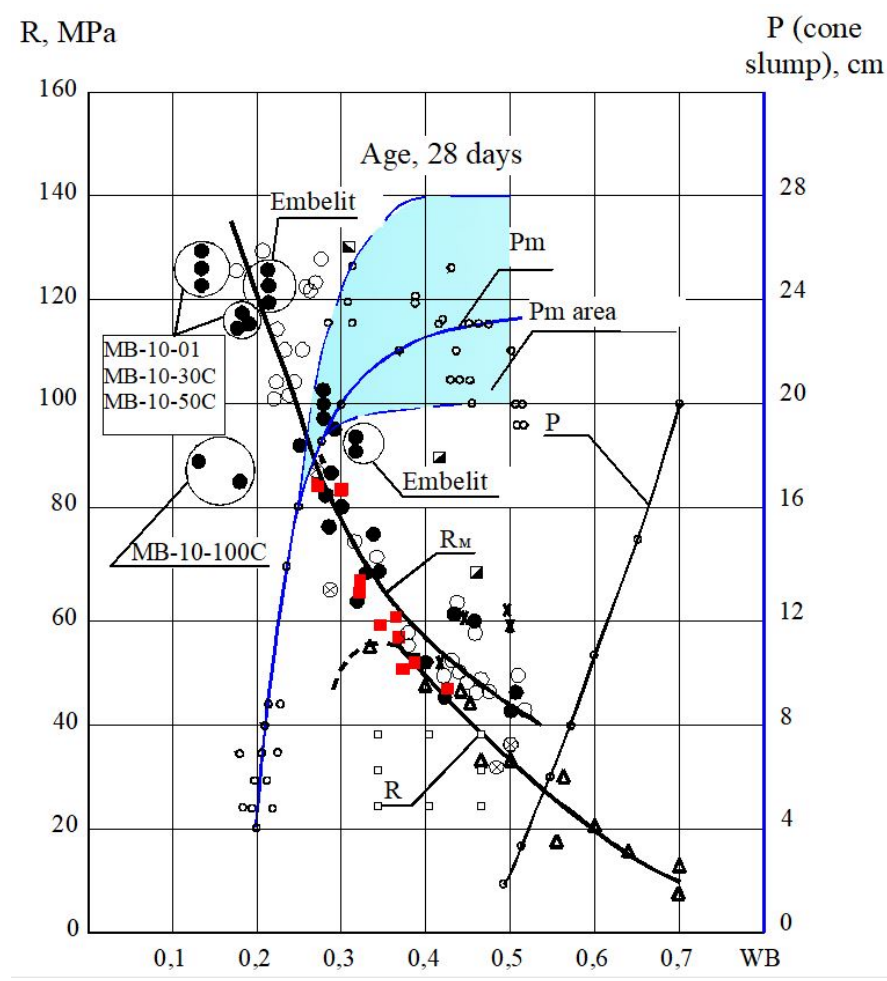

$\Delta$ - concrete (unmodified) with no additions;

$\bullet \mathbf{x} \otimes \mathbf{\square}$-modified concrete;

- V.G.Batrakov, K.G.Sobolev, MB modifier data;

- - S.S.Kaprielov, A.V.Sheinfeld, concrete with MB and Embelit;

x - A.T.Kovalyov, I.A.Tsepilova, concrete with SP "Polyplast";

$\square, \mathbf{\square}-$ V.I.Kalashnikov, concrete with ground meal and MS;

incl. - reactive powder concrete;

- As per Biotech data by Lignopan B-1;

- Own data;

- Workability of concrete mixes.

Pm - workability of modified concrete mixes, P - workability of unmodified concrete mixes, RM water-binder dependence for modified concrete, R - water-binder dependence for unmodified concrete

Fig. 1. Dependences of compressive strength of concrete R on concrete mix workability $\mathrm{P}$ and waterbinder ratio for both unmodified and modified concrete with superplasticizers and organo-mineral additives.

According to analysis of previous and our own results [7, 8] consistent aggregate grading with minimum void, accordingly with maximum packed density under optimum content of dispersed particles in concrete is to be applied to make mortars and concrete with stable properties and less variations in values. Water-binder ratio therewith is to be taken depending on the desired value of the required property, mortar or concrete by substituting part of cement in the cement system with either active or inert mineral dispersed additive (filler) by regulating workability with adding plasticizers.

The proposed solution enables to simplify proportioning as different combination of aggregates is not required for each proportion. Strict requirements are imposed on the filler that should be slightly changing the mortar workability and cementitious composite 
strength when substituting part of cement. Comparative analysis of various fillers being byproducts and materials for making mortars and asphalt-concrete in the Republic of Bashkortostan has been made by us.

Main reasons resulting in instabilities of concrete characteristics, variability of aggregate grain-size distribution and aggregate voidage variation related thereto, variability of fractions less than $0.16 \mathrm{~mm}$ in the aggregate and silty-clayed particles variation are to be excluded to make modified concrete with the required properties. Adding of mineral additives, such as active ones e.g. amorphous silica, as well as application of cement with the required content and phase relation $\beta-C_{2} S, C_{3} S$ in combination with the appropriate chemical additive are very efficient to prevent from negative destruction processes and retention of the reliable properties in the required life cycle of concrete products and constructions maintenance. $R \& D$ and innovation efforts resulted in large-scale manufacture of concrete with superplasticizers [9, 10]. Nowadays in the Republic of Bashkortostan actually all companies making concrete of grade V15 and higher use superplasticizers. Information on some of our projects for making concrete is given below. A batch of prestressed reinforced concrete paving slabs PDNm-AtIV made of concrete with modifier Relamix T-2 with the reduction of cement consumption and time for curing was manufactured in OOO "Zhelezobetonnyi zavod No.1" (Sterlitamak, the Republic of Bashkortostan). A batch of pipe culverts is manufactured by State Unitary Enterprise "Bashkiravtodor" of concrete mixes with organo-mineral modifiers thereby resulting in better quality of the product surface with the reduction of cement consumption $[11,12]$. A batch of ready-mix concrete BSG V30 P3 F300 W6 with high performance properties obtained due to application of multicomponent concrete modifier PFM-NLK was prepared by Concrete Batch Plant OOO "Ufimskaya Betonno-Rastvornaya Company" for making flight strip.

The engineered approach and quantitative evaluation for reducing reinforced steel consumption $[13,14]$ have been applied in engineering of a number of cast-in-place highrise apartment houses in Ufa. A400 rebar and V25 concrete were substituted by A500S rebar and V40 concrete in one of the facilities, thereby reducing consumption of reinforced steel up to $49.7 \%$ (Table 1 ).

Table 1. Total saving of reinforced steel.

\begin{tabular}{|c|c|c|c|}
\hline \multirow{2}{*}{$\begin{array}{l}\text { Original } \\
\text { grade of } \\
\text { concrete }\end{array}$} & \multirow{2}{*}{$\begin{array}{c}\text { Alternate grade } \\
\text { of concrete }\end{array}$} & $\begin{array}{c}\text { Saving of reinforced steel of grades A } 400\left(\mu_{0}=0,02\right) \\
\text { /A 500C }\left(\mu_{0}=0,015\right), \%\end{array}$ \\
\cline { 3 - 4 } & & For alternate grade & $\begin{array}{c}\text { In relation to previous } \\
\text { alternate grade of concrete }\end{array}$ \\
\hline $\mathrm{V} 25$ & $\mathrm{~V} 35$ & $10.5 / 9.3$ & $-/-$ \\
\hline $\mathrm{V} 25$ & $\mathrm{~V} 40$ & $13.5 / 11.9$ & $2.7 / 2.4$ \\
\hline $\mathrm{V} 25$ & $\mathrm{~V} 50$ & $17.9 / 15.8$ & $2.8 / 3.46$ \\
\hline $\mathrm{V} 25$ & $\mathrm{~V} 60$ & $20.5 / 18.2$ & $1.5 / 1.4$ \\
\hline $\mathrm{V} 25$ & $\mathrm{~V} 70$ & $22.4 / 19.8$ & 2.1 \\
\hline
\end{tabular}

Comparison between two design solutions being developed to construction design stage ("reinforced-concrete structures" section) has revealed that consumption of A500S main rebars is reduced to $25 \%$, while total consumption of A500S rebars (both main and structural one) is reduced to $17 \%$ as compared with A400 (AIII) rebars.

The results for reinforced steel consumption reducing together with efficient combination of higher grade concrete were considered at amending the "reinforcedconcrete structures" section of the construction design "Ten-storey cast-in-place residential house No.1 "Kaskad" (ICF walls) in Rossiyskaya street, Ufa" and when constructing 25- 
storey cast-in-place residential houses Nos.9 \& 10 in Ufa in Bakalinsky residential area of Ufa $[15,16]$.

Feasibility solution for optimization and efficient application of modified high strength concrete was justified and implemented under R\&D results at engineering [17, 18], and making concrete at monolithic construction of 25 -storey residential houses Nos. 9 \& 10 in Bakalinsky residential area of Kirovsky District of Ufa.

Consumption of concrete per one storey was $152 \mathrm{~m}^{3}$ for slabs, and $127 \mathrm{~m}^{3}$ per walls according to the original project. After application of the engineered solution the project costs amounted to $152 \mathrm{~m}^{3}$ for slabs, and $85 \mathrm{~m}^{3}$ for walls. Consumption of steel for reinforcing of concrete structures for one storey of residential houses Nos.9 \& 10 were as follows: according to the original project with application of V25 concrete and rebars A400 (AIII) for slabs $-43.4 \mathrm{t}$, for walls - 16.1t. Total: 59.5t. After application of the engineered solution for using V35 concrete and rebars A500S consumption of rebars reached: $32.4 \mathrm{t}$ for slabs and $12.2 \mathrm{t}$ for walls $[19,20,21]$. Total: $44.6 \mathrm{t}$. Total saving of concrete amounted to $42 \mathrm{~m}^{3}$ for one storey and that of steel $-14.9 \mathrm{t}(25.1 \%)$ for one storey by main rebars. Total saving of materials and work costs exceeded RUR $25 \mathrm{mln}$.

According to amendment made to the "reinforced-concrete structures" section wall thickness of 17 storeys of residential houses Nos.9 \& 10 in Bakalinsky residential area was reduced from $300 \mathrm{~mm}$ (by original project) to $200 \mathrm{~mm}$ by substituting concrete and rebar grades, weight of the buildings being reduced therewith by several thousands of tons.

\section{Results}

The results of the feasibility study for efficient application of high-strength modified concrete $[22,23,24]$ and of high-strength rebars were adopted to the construction of 25 storey cast-in-place residential houses Nos. 9 \& 10 in Bakalinsky residential area of Ufa. Actual discrepancy of data between theoretical technical and economical solution and actual expenses for materials at construction amounted to: about $4.5 \%$ for concrete and about $6 \%$ for rebars.

In accordance with the engineered feasibility solution [25] original AIII rebar grade is substituted to A500S high-strength rebar at efficient combination with the modified high strength concrete. Developed and registered PC program "Calculation of efficient consumption of reinforced steel with respect to cost efficiency for alternate cross-section of the flexible element" [26] was used.

\section{Conclusions}

The proposed analytical tools engineered and widely applied in the Republic of Bashkortostan enable to define practical areas for applying efficient grades of concrete and reinforced steel in concrete elements accompanied by feasibility study at the design stage and to make quantitative evaluation of efficiency thereof, which is more important when choosing modified concrete and advanced rebars for making cast-in-place concrete facilities.

\section{References}

1. V. Braun, Raskhod armatury v zhelezobetonnykh konstruktsiyakh (Stroyizdat, Moscow, 1993) 
2. A.S. Salov, L.I. Khabibullina, A.I. Gabitov, E.A. Udalova, V.A. Timofeev, A.A. Timofeev, Istoriya nauki i tekhniki, 11, 37-43 (2017)

3. A.I. Bedov, V.V. Babkov, A.I. Gabitov, A.S. Salov, Vestnik MGSU, 8, 76-84 (2012)

4. V.I. Vinnichenko, A.N. Ryazanov, MATEC Web of Conferences 116, 01020 (2017).

5. V.I. Vinnichenko, A.N. Ryazanov, N.Y. Vitsenko, Construction materials, 10, 76-83 (2016)

6. A.I. Bedov, A.M. Gaysin, A.I. Gabitov, Textile industry technology, 3(369), 231-236 (2017)

7. A.I. Bedov, A.S. Salov, V.V. Babkov, A.I. Gabitov, I.V. Nedoseko, Current problems for calculation of reinforced concrete constructions, buildings and structures for emergency impact, 503-507 (2016)

8. A.N. Ryazanov, V.I. Vinnichenko, I.V. Nedoseko, V.A. Ryazanova, A.A. Ryazanov, Construction materials 1-2, 18-22 (2018)

9. S.H. Aminov, I.B. Strugovec, I.V. Nedoseko, V.P. Klimov, V.V. Babkov, Culvert pipes for asphalt concrete roads, 10, 2 (2003)

10. A.M. Gaisin, V.V. Babkov, Construction materials, 1, 55-58 (2016)

11. A.G.Tamrazyan, Concrete and reinforced concrete: problems and prospects, 7, 51-54 (2014)

12. D.N. Sursanov, A.B. Ponomaryov, Bulletin of National Research Perm Polytechnic University Construction and Architecture, 4, 144-165 (2015)

13. A.I. Bedov, A.I. Gabitov, A.S. Salov, A.M. Gaisin, L.I. Khabibullina, Building and reconstruction, 6(74), 3-12 (2017)

14. A.A. Semenov, A.I. Gabitov, Static analysis, 1, 152 (2005)

15. A.I. Bedov, A.S. Salov, A.I. Gabitov, D.V. Kuznetsov, E.A. Sadykova, International Journal for Computational Civil and Structural Engineering, 13 No. 4, 37-46 (2017)

16. A.M. Gaisin, S.Y. Samokhodova, I.V. Nedoseko, A.Y. Paymetkina, Residential construction, 5, 36-40 (2016)

17. V.G. Batrakov, Concrete modifiers: new opportunities and prospects, 10, 4-7 (2006)

18. S.S. Kaprielov, V.I. Travush, N.I. Karpenko, A.V. Sheynfel'd. Modified concretes of a new generation in the Moscow-City construction sites. Part I, 10, 13-17 (2006)

19. S.I. Kryshov, I.S. Kurilyuk, Housing construction, 7, 3-5 (2016)

20. A.M. Gaisin, R.R. Gareev, V.V. Babkov, I.V. Nedoseko, S.Y. Samokhodova, Construction materials, 4, 82-86 (2015)

21. A.N. Ryazanov, V.I. Vinnichenko, Bulletin of Voronezh State Technological University, 9 No 6-2, 22-24 (2013)

22. V.I. Kalashnikov, Calculation of high-strength self-compacting concrete compositions, 10, 4-6 (2008)

23. V.I. Vinnichenko, A.N. Ryazanov. Ecological indices of manufacture of Portland cement clinker and production of the dolomite clinker C. 01020 (2017)

24. A.N. Ryazanov, V.I. Vinnichenko, News of Higher Educational Institutions. North Caucasian Region. Series: Technical Sciences, 1(176), 115-117 (2014)

25. D. Balageas, C.P. Fritzen, A. Guemes, Structural Health Monitoring, 496 (2006)

26. G.Clark. Challenges for concrete in tall, 7, 103-112 (2014) 